\title{
Using the UTAUT2 Model to Determine Factors Affecting Adoption of Mobile Banking Services: A Qualitative Approach
}

\author{
https://doi.org/10.3991/ijim.v12i4.8525 \\ Malik Khlaif Gharaibeh( $\left.{ }^{\bowtie}\right)$, Muhammad Rafie Mohd Arshad \\ Universiti Sains Malaysia, Penang, Malaysia \\ malikgharaibeh2018@gmail.com \\ Natheer K. Gharaibh \\ Taibah University, Yanbu, Saudia Arabia
}

\begin{abstract}
The main purpose of this study is to investigate the determinants that affect the adoption of mobile banking services in Jordan. The current study extends the Unified Theory of Acceptance and Use of Technolgy2 (UTAUT2) by adding two important factors, mass media and trust utilizing by seven respondents based on qualitative approach, this study shows that the adoption of mobile banking is positively and significantly influenced by the mass media, trust, effort expectancy, performance expectancy, facilitating conditions, and social influence. In contrast, hedonic motivation seems to be insignificantly related to adoption of mobile banking services. There are numerous variables affect the of adoption mobile banking. While most previous studies address the relationship between these factors and the attitudes toward mobile banking services by using the quantitative approaches, this study adopts qualitative approach (focus group method) to provide further insight into the main factors which affect adoption of mobile banking. Furthermore, the current study extends the original UTAUT2 by testing the impact of two new variables. This is considered the important contribution in the paper.
\end{abstract}

Keywords-Mobile banking, UTAUT2, mass media, effort expectancy, Jordan

\section{Introduction}

Recently, using advanced technologies (broadband and mobile, etc.) have been growing considerably among consumers and service providers in financial sector, as well as employing these new technologies affect in change the way of handling with service delivery $[1,2]$. The banks' concerns shifting consumers to technology enabled self-service channels (e.g. ATMs, internet banking, and mobile banking services) and mobile device even to partly decline the role of traditional branches [3].Such dynamic environments make banks deciding when and to which degree to spend in mobile banking. Mobile Banking provides a new way of accessing bank account by mobile devices and so allows for a fully new interaction channel between bank and customer 
$[4,5]$. In this regard, the understanding and prediction of determinants that affect using of mobile banking services by customer is becoming a vital subject. [6] The newest statistics showed that there are already around 4.77 billion mobile phone users worldwide. The statistics also revealed more than 38 percent of mobile phone users were Smartphone users [7].

However, banks continuously trying to attract customers to use such service but faces many obstacles which make its usage uncertain [8,9]. At the global level, many researchers investigated the adoption of mobile banking services and concluded that many countries are still suffering from low-level customer adoption of mobile banking services [10-12]. Zhang, Zhu, and Liu [13] mention, mobile banking currently is in its early stages and failed to get the trust of banking consumers. Also as Shaikh and Karjaluoto [14] as well as Dineshwar and Steven [15] note, the usage of mobile device to perform banking transactions and access bank accounts has not increased as expected which is in consistence with Hanafizadeh, Behboudi, Koshksaray, and Tabar [12] stated that despite technological advancement and increased availability of mobile banking services, the penetration rate among users does not match expectations a fact that warrants examination into its causes.

In the context of Jordan, Gharaibeh and Arshad [16] mentioned that in spite of past experience on mobile banking adoption by Jordanian banks, the usage of mobile banking services among consumers in the Jordan is still low. Only $8 \%$ of the banking consumers use mobile banking services, leaving $92 \%$ do not use it. They also concluded that $79.3 \%$ of the customers mentioned that their banking needs are met without mobile banking. However, previous mobile banking adoption studies depend on greatly on quantitative methods and have found little consensus. Meanwhile there is lack of published qualitative papers on perceptions of mobile banking usage, particularly in developing countries. The main aim of the current study is to understand the determinants affecting users' adoption of mobile banking services by extending UTAUT2 model with two variables; mass media and trust (for Jordanian community) in hope to raise their intentions to use mobile banking services. In order to do that, the present study addressed one main research question: "What factors affect the usage of mobile banking from the user's viewpoint?"

\section{$2 \quad$ Research Model}

Despite that UTAUT2 model is considered a new model since its emerging in 2012, researchers in the field of IS are increasingly testing its suitability, validity, and reliability to explain technology adoption in different contexts [17-25]. Compared with other models, UTAUT2, created an essential enhancement in the variance explained in technology use, i.e., 40 percent to 52 percent in UTAUT, while 56 percent to 74 percent in UTAUT2 [17]. Furthermore, UTAUT2 is more applicable to this study as it focused on customer use context. In contrast, IDT and original UTAUT are more applicable for employee use context [26]. Rondan et al., [27] conducted a comparison study among technology acceptance models which include; TAM, TAM2, TRA, UTAUT, and UTAUT2. Data were collected through questionnaires from mo- 
bile internet users. They used WarpPLS (non-linear model) and partial least squares (linear model) for each model. They concluded that UTAUT2 model has a better explanation power than other models. In addition, TAM2 does not seem to give a better explanation for the adoption and acceptance of new technologies than the original TAM. Based on above discussion, it is expected that UTAUT2 is a preferable model in this study.

\section{$3 \quad$ Research Method}

According to Sagoe [28], focus group discussions generate data that may not surface in individual interviews or survey research. Furthermore, the focus group provides a wider understanding of members' opinions, beliefs, and suggestions about the research topic [29]. In this study, focus group method was performed in order to gather deep information about the constructs of the research model. The focus group contained seven members representing different ages, educational levels, and jobs, as shown in Table 1. According to [30], four to six members is considered appropriate to generate adequate content from a focus group. The sample of the focus group consisted of banking customers who are using mobile banking services and have both a bank account and a smartphone.

Table 1. Demographic profiles of focus group members

\begin{tabular}{|c|c|c|c|}
\hline Member & Age & Education level & Job \\
\hline A1 & 53 & Bachelor & Lawyer \\
\hline A2 & 40 & Master & Teacher \\
\hline A3 & 35 & Bachelor & Reporter \\
\hline A4 & 34 & Bachelor & Teacher \\
\hline A5 & 25 & Master & Engineer \\
\hline A6 & 22 & Bachelor & University Student \\
\hline A7 & 21 & Bachelor & University Student \\
\hline
\end{tabular}

The focus group was managed on the 3rd of May, 2017. Before starting the discussions, all members were informed about the recording device (Digital Audio Recorder) to assist the researcher in analyzing the discussions. The researcher also informed all participants that the provided information would be used for completing the research requirements and treated with the strictest privacy. The session began with giving a general information about the research topic and objectives. Then, a free discussion with the researcher was conducted to welcome any questions regarding the research. The researcher also shared some guidelines and motivated the participants to answer during the session. A semi-structured method was used in the discussion so as not to be over-detailed and focused on the topic with regards to intention to use mobile banking services. All members were encouraged to freely answer in their own words for the open-ended questions. This took about one and half hour, then all members were thanked by the researcher for their contributions. 


\section{$4 \quad$ Findings}

The analysis of the focus group was performed using three procedures. First, all arguments and discussions among participants were transcribed. Second, the researcher read and investigated the transcripts carefully. Finally, all construct questions about the research model were analyzed. The findings from the analysis are summarized below.

\subsection{Mass media}

In this study, mass media is defined as channels of communication-whether written, broadcast, or spoken - that reach a large number of audience. This includes television, radio, advertising, Internet, newspapers, magazines, and so forth [31]. The following arguments were the findings of the discussion among the members.

All members agreed that different mass media channels help the customers obtain knowledge about mobile banking services. Member A1 commented that, "watching the television reports about mobile banking services will encourage customers to use mobile banking services, through delivering information and disseminating the usefulness about using it." Member A3 mentioned that using mass media by banks enables large number of audience to get information at the same time.

In addition, Member A4 answered that mass media are used as a promotional tool by banks, especially that every house has all mass media channels, such as television, radio, and the internet. Member A5 confirmed previous comments saying, "In my opinion, I have not seen any reports about using mobile banking but it is a good idea especially the adoption of mobile banking among customers is now at the early stage of prevalence so the customers need more information to know it. Member A6 confirmed the previous opinions and mentioned that he thinks that different mass media channels can construct a good idea about any new technology. Finally, Member A7 contradicted previous comments because he thinks that customers look at benefits of using this technology. However, if the customers do not find any, they will not use it.

Based on these arguments, the evidence indicates that mass media positively affect the adoption of mobile banking services.

\subsection{Trust}

Trust is defined as the subjective expectation with which consumers believe that a specific transaction occurs in a way consistent with their confident expectations [32]. The following points are the results of the discussion among the members.

In this study, there are two dimensions of customers that trust mobile banking services: trust in telecommunication operators to provide a secure data connection for performing mobile banking transactions, and trust in banks to offer secure mobile banking. In general, all members mentioned that they trust their banks because the banks already have all their personal accounts, so the banks are trustworthy.

All members said that the banks should provide them with a high level of security to keep the customers' information safe. Member A1 said, "The trust in banks is a 
significant matter in the adoption of mobile banking services, so I have no problem with conducting my banking transactions via mobile banking way." Member A2 said, "Customers must trust mobile banking services because it originates from the banks, which provide other services, such as ATM and internet banking and also trustworthy, they are looking for providing customers with new and best services."

Member A3 and A4 mentioned that both banks and telecommunication operators should have awareness about security and privacy concerns. They too should follow ethical principles when dealing with personal information. Similarly, Member A5 said, "the banks must protect their customers by using the highest security systems, to keep our accounts and personal information safe. Members A6 and A7 confirmed the previous views and they mentioned that the more trust in the mobile banking services leads to more intention to use.

Based on these arguments, it is clear that trust has significant effects on adoption of mobile banking services.

\subsection{Performance expectancy}

Performance expectancy is defined as the extent to which using technology will offer benefits to a customer in performing certain activities [33]. The following viewpoints are the findings of the debate among the respondents.

All members mentioned the benefits of mobile banking services because the services help them to accomplish their banking transactions more quickly and efficiently. Member A1 said, "I used mobile banking three years ago, and I found it very useful in conducting the banking transactions.

Likewise, Members A2, A3, and A6 mentioned that by using the mobile banking services, they can conduct their banking transactions anytime and anywhere. Member A2 stated, "by using the mobile banking services, I do not need to drive my car and visit the bank branch or ATM". Meanwhile, Member A6 commented that mobile banking services enable him to conduct banking transactions easily, especially with the crowd in the bank. Member A5 agreed with Members A6 and A2 by saying, "I found that mobile banking service has two advantages high level of quality and saving time, so I recommend others to use this service." Member A4 and A7 strongly confirmed the previous discussions. Member A4 stated that the banks must show the benefits derived from using mobile banking services to the customers because they need to understand their values before using. This will increase their willingness to use such a system. As mentioned in mass media arguments, Member A7 stated that customers look for benefits in using this technology more than other issues.

Based on the previous arguments, the evidence indicates that performance expectancy has a positive impact on adoption of mobile banking services.

\subsection{Effort Expectancy}

Effort expectancy is defined as the degree of ease related to customer's use of technology [33]. The following arguments reflect the members' observations. 
All members indicated that any mobile application must be easy to use and learn to enable the users or customers to use it. Members A1 and A2 confirmed that while Member A3 said, "I used mobile banking six months ago and found it easy to use, so I intend to use this service continually in the future."

Moreover, Members A4 and A5 mentioned that any customer who does not have high level of internet experience is expected to install the mobile banking application because it has an easy registration process. Member A1 described that by saying, "In the past, I used to conduct my banking transactions via internet banking, but now mobile banking channel is more suitable for me because my PC or Laptop is not always switched on contrary to a smartphone."

All members indicated that their interaction with mobile banking is clear and understandable. Members A1, A6, and A7 agreed that as the banks offer both languages, Arabic and English, there is no difficulty with using such applications. In addition, Member A4, who is a customer for Housing Bank, mentioned that although his experience with the internet is moderate, but he used mobile banking services on monthly basis without any need of help.

Finally, all members agreed that the process of mobile banking services is easy to remember especially through accumulated usage. They too agreed that performing banking transactions via smartphones does not take much time.

The analysis from previous arguments indicates that effort expectancy has a positive impact on adoption of mobile banking services.

\subsection{Social influence}

Social influence is defined as the degree in which an individual perceives that importance of others' opinion in believing he or she should use the new system [33]. The following arguments were the findings of the discussion among the members.

Members A2 and A3 stated that friends' suggestions and recommendations would affect their decisions to use any new thing. Member A1 confirmed with A2 and A3 by saying that "when one of my friends uses a new technology that usually plays a vital role in affecting my decision, especially if he recommends me to use it, I will take into account the importance of using it because I trust my friends"

Similarly, all members mentioned that family members/relatives have an influence on their decision to use mobile banking. Member A4 said, "I used mobile banking services one year ago, my brother recommended me to use it." Member A3 also noted that when his relatives use mobile banking services, for that he decided to use mobile banking services. Member A5 commented, "I used mobile banking services more than three years ago, through these years, I affected my brothers and relatives to use mobile banking services." He also mentioned that as mobile banking services originate from trusted banks, he has no problem to use it.

Finally, the members agreed that mobile banking services are a status symbol in the community. Members A6 and A7 noted that they used the latest technology on their smartphones. Member A6 said, "Advancement of electronic services by banks such as mobile banking make both banks and customers have a status symbol in the community." Whereas, Member A7 said, "As for me and my friends, using mobile 
banking service is a normal part of our life when we need to perform banking transactions because really it is high value."

Based on these arguments, the evidence indicates that social influence has a strong impact on adoption of mobile banking services.

\subsection{Facilitating conditions}

Facilitating conditions are defined as the degree to which an individual believes that an organizational and technical infrastructure exists to support the use of the system [33]. The following arguments are the findings of the discussion among the members.

All members pointed out the availability of required resources to use mobile banking services. Members A1, A2, and A5 admitted the availability of the internet services in cities, towns, and villages inside Jordan. Member A1 confirmed this view: "I think a high rate of Jordanian have the Smartphone and easily they can connect the internet." Member A2 commented: "The internet service is available in all areas and Smartphones have become cheap so a wide rate of Jordanians can use mobile banking services easily. Member A5 added, "I can access the internet anywhere and anytime and I can access the website through mobile banking easily".

All members mentioned that mobile banking is compatible with other technologies they use. Member A6 stated, "I can do my banking transactions on the Smartphone the same way in laptop or computer, there is no difference". Member A7 also confirmed this view by saying "I can conduct my banking transactions in applications in the Smartphone and this fewer steps when I conduct via computer".

All members mentioned that they get help from the banks if they have difficulties using mobile banking. Member A3 said, "I went to the bank and they downloaded the application for me and I got support from them on how to use mobile banking". Member A4 added, "I did not face problems with using mobile banking but the bank will help me if I face problems".

According to these arguments, the evidence indicates that facilitating conditions have a strong impact on adoption of mobile banking services.

\subsection{Hedonic motivation}

Venkatesh et al., [17].defined hedonic motivation as fun or pleasure derived from using a technology The members raised the following points.

Most members agreed that using mobile banking saves their time and effort, but is not enjoyable or interesting. Members A1, A2, and A5 mentioned that they searched about enjoyment and interesting things in other applications which include games or funny videos. Member A2 confirmed this view: "I used mobile banking services because it saves time when conducting my banking transactions but I do not perceive it as an enjoyment or interesting process". Similarly, Member A5 said: “mobile banking would be a useful application but when I need the fun or to kill my time I prefer to play games on my Smartphone”. In this regard, Members A6 and A7 have other opin- 
ions. Member A7 mentioned that he found enjoyment using the technology and indirectly from using mobile banking services.

All members agreed that the services in mobile banking do not arouse their curiosity. Members A2, A3, and A4 mentioned that mobile banking services have the same services provided by internet banking. Moreover, Member A4 said, "Not all services I can perform through mobile banking such as deposit funds and money withdrawal but I can benefit from mobile banking services in transferring money and paying bills".

According to these arguments, the evidence indicates that hedonic motivation has a non-significant impact on adoption of mobile banking services.

\section{Discussion and implication}

The main focus of this study was to shed light on the underlying variables that adoption of mobile banking. In general, the findings reveal that mass media, trust, effort expectancy, performance expectancy, facilitating conditions, social influence are salient in determining clients' mobile banking adoption. The finding that mass media exert impact on mobile banking adoption highlights the importance of awareness in the accelerating process of mobile banking usage. Increasing awareness of mobile banking services leads to raising acceptance and usage levels in mobile banking services. Hence, it is vital to perform awareness campaigns that would discover any misunderstandings about mobile banking services and the benefits of their adoption. The awareness campaigns could be more effective if all customers in Jordan can be reached, utilizing all mass media channels, such as TVs, radios, advertisements, and newspapers. These efforts will improve the chances of mobile banking service adoption among customers.

The results showed trust as an important variable that affects intention to use mobile banking services, particularly when clients are required to give confidential personal information such as contact information or identity card numbers. The findings showed that in order to raise mobile banking services usage among customers, the banks should increase the security and trust level in their E-Systems. Accordingly, factors that affect users' trust in mobile banking services should be addressed in the banks' strategies by studying them and raising their roles. In addition, to expand trust in mobile banking services, banks should create a reliable communication channels with customers. For example, engaging customers to participate in new policies and decisions can boost their trust in mobile banking applications. Furthermore, it is important that banks encourage customers to trust mobile banking services by improving confidence levels through the use of high security systems to keep the accounts and data safe.

The finding from performance expectancy analysis reveals that customers will consider adopting mobile banking services if using the system will enhance customers' job performance and assist them to achieve both tangible and intangible advantages of their banking transactions. In other words, mobile banking services are seen as a useful strategy and administrative tool that customers can attain benefits from adopting the system, such as in enhancing efficiency and effectiveness of their daily banking 
transactions. The salient impact of effort expectancy was also validated in the proposed research model, since the members in focus group have a good and prior experience in using Internet banking services and they mentioned about ease of use application in their comments; therefore, it is easy for potential mobile banking service users to use these services. Customers will consider adopting mobile banking services if using them is easy for their banking transactions. Thus, with higher level of ease of use for these services, customers are more likely to adopt them.

The findings also indicates to the importance of social influence, the customers will consider adopting mobile banking services based on opinions provided by their important and surrounding people, such as friends, colleagues, family members, and relatives. Thus, with higher level of positive opinions of their social circle, such as family and friends, regarding the service, customers are more likely to adopt mobile banking services, and vice versa. In regard with facilitating conditions, this factor was found to be very important in mobile banking adoption. It appears to the customers that when they perceive they have adequate knowledge about the service, a proper smartphone, and help from the bank to assist them with any difficulties while using the services, their intention to use them will be increased. In fact, if banks show a high level of interest in customers' needs, their customers are more likely to adopt mobile banking services.

In contrast, the results from the focus group analysis indicate that hedonic motivation has a non-significant impact on intention to use mobile banking services. This is because most members mentioned that hedonic motivation does not play a role in customers' intention to use mobile banking services. Although they observed that mobile banking services enable them to perform their banking transactions quickly with ease of use, they did not see that mobile banking is enjoyable smartphone.

\section{Conclusion}

This study empirically tested an integrative model to explain the decision to use mobile banking at a customer level. The findings reveals that the most vital constructs explaining mobile banking adoption are mass media, trust, effort expectancy, performance expectancy, facilitating conditions, and social influence. Contradictorily, hedonic motivation seems to be insignificantly associates with adoption of mobile banking services. There are numerous variables affect the of adoption mobile banking, the current article provides the initial foundation to developing a theoretical background which is needed for assessing mobile banking adoption process. This study, like any other study, has its limitations, we examine a specific type of electronic banking context. Future research would also investigate other electronic banking channels such as mobile payment and online banking In addition, the results are not able to be generalized through statistics like the case of the quantitative method. The findings of quantitative study would be more useful than wide in nature, worth to be quantitatively investigated in future researches to deliver more generalizable results. We also encourage further researchers to address more investigations on the relationship between hedonic motivation and mobile banking adoption, which the result in this study was 
obtained through focus group in oppose to all previous studies results. Finally, the focus group was limited to only one group, organized in Irbid, and other focus groups in other cities were very difficult to manage because of the high level of cooperation is needed to communicate with the members, as well as work responsibilities and availability for each of them.

\section{$7 \quad$ References}

[1] Jun, M. and S. Palacios, Examining the key dimensions of mobile banking service quality: an exploratory study. International Journal of Bank Marketing, 2016. 34(3): p. 307-326. https://doi.org/10.1108/IJBM-01-2015-0015

[2] Oliveira, T., et al., Extending the understanding of mobile banking adoption: When UTAUT meets TTF and ITM. International Journal of Information Management, 2014. 34(5): p. 689-703. https://doi.org/10.1016/j.ijinfomgt.2014.06.004

[3] Mehrad, D. and S. Mohammadi, Word of Mouth impact on the adoption of mobile banking in Iran. Telematics and Informatics, 2016.

[4] Moser, F., Mobile Banking: A fashionable concept or an institutionalized channel in future retail banking? Analyzing patterns in the practical and academic mobile banking literature. International Journal of Bank Marketing, 2015. 33(2): p. 162-177. https://doi.org/10.1108/IJBM-08-2013-0082

[5] Afshan, S. and A. Sharif, Acceptance of mobile banking framework in Pakistan. Telematics and Informatics, 2016. 33(2): p. 370-387. https://doi.org/10.1016/j.tele.2015.09.005

[6] Thakur, R., What keeps mobile banking customers loyal? International Journal of Bank Marketing, 2014. 32(7): p. 628-646. https://doi.org/10.1108/IJBM-07-2013-0062

[7] Statista, Number of mobile phone users worldwide from 2013 to 2019 (in billions). 2017.

[8] Lin, H.-F., An empirical investigation of mobile banking adoption: The effect of innovation attributes and knowledge-based trust. International journal of information management, 2011. 31(3): p. 252-260. https://doi.org/10.1016/j.ijinfomgt.2010.07.006

[9] Mohammadi, H., A study of mobile banking usage in Iran. International Journal of Bank Marketing, 2015. 33(6): p. 733-759. https://doi.org/10.1108/IJBM-08-2014-0114

[10] Alsoufi, A. and H. Ali, Customers perception of mbanking adoption in Kingdom of Bahrain: an empirical assessment of an extended tam model. International Journal of Managing Information Technology, 2014. 6(1).

[11] Alalwan, A.A., et al., Adoption of Mobile Banking in Jordan: Exploring Demographic Differences on Customers' Perceptions, in Open and Big Data Management and Innovation. 2015, Springer. p. 13-23. https://doi.org/10.1007/978-3-319-25013-7 2

[12] Hanafizadeh, P., et al., Mobile-banking adoption by Iranian bank clients. Telematics and Informatics, 2014. 31(1): p. 62-78. https://doi.org/10.1016/j.tele.2012.11.001

[13] Zhang, L., J. Zhu, and Q. Liu, A meta-analysis of mobile commerce adoption and the moderating effect of culture. Computers in human behavior, 2012. 28(5): p. 1902-1911. https://doi.org/10.1016/j.chb.2012.05.008

[14] Shaikh, A.A. and H. Karjaluoto, Mobile banking adoption: A literature review. Telematics and Informatics, 2015. 32(1): p. 129-142. https://doi.org/10.1016/j.tele.2014.05.003

[15] Dineshwar, R. and M. Steven. An investigation on mobile banking adoption and usage: A case study of Mauritius. in Proceedings of 3rd Asia-Pacific Business Research Conference. 2013. Kuala Lumpur.

[16] Gharaibeh, M. and M.R.M. Arshad, Current Status of Mobile Banking Services in Jordan. World Applied Sciences Journal, 2016. 34(7): p. 931-935. 
[17] Venkatesh, V., J.Y. Thong, and X. Xu, Consumer acceptance and use of information technology: extending the unified theory of acceptance and use of technology. MIS quarterly, 2012. 36(1): p. 175-178.

[18] Oechslein, O., M. Fleischmann, and T. Hess. An Application of UTAUT2 on Social Recommender Systems: Incorporating Social Information for Performance Expectancy. in (HICSS), 2014 47th Hawaii International Conference on System Sciences. 2014. IEEE.

[19] Slade, E., M. Williams, and Y. Dwivdei. Extending UTAUT2 To Explore Consumer Adoption Of Mobile Payments. in Proceedings of the UK Academy for Information Systems Conference, March. 2013.

[20] Hew, J.-J., et al., What catalyses mobile apps usage intention: an empirical analysis. Industrial Management \& Data Systems, 2015. 115(7): p. 1269-1291. https://doi.org/10.1108/IMDS-01-2015-0028

[21] Xu, X. Understanding users' continued use of online games: An application of UTAUT2 in social network games. in The Sixth International Conferences on Advances in Multimedia. 2014.

[22] Nair, P.K., F. Ali, and L.C. Leong, Factors affecting acceptance \& use of ReWIND: validating the extended unified theory of acceptance and use of technology. Interactive Technology and Smart Education, 2015. 12(3): p. 183-201. https://doi.org/10.1108/ITSE-022015-0001

[23] Yang, S., Understanding Undergraduate Students' Adoption of Mobile Learning Model: A Perspective of the Extended UTAUT2. Journal of Convergence Information Technology, 2013. 8(10): p. 969-979. https://doi.org/10.4156/jcit.vol8.issue10.118

[24] Raman, A. and Y. Don, Preservice teachers' acceptance of Learning Management Software: An application of the UTAUT2 model. International Education Studies, 2013. 6(7). https://doi.org/10.5539/ies.v6n7p157

[25] Huang, C.-Y., et al. Deriving factors influencing the acceptance of Pad Phones by using the DNP based UTAUT2 framework. in Technology Management in the IT-Driven Services (PICMET), 2013 Proceedings of PICMET'13:. 2013. IEEE.

[26] Rogers, E., Diffision of innovations. New York: Free Press, 2003.

[27] Rondan, C.F.J., G.J. Arenas, and C.P.E. Ramírez, A comparison of the different versions of popular technology acceptance models: A non-linear perspective. Kybernetes, 2015. 44(5): p. 788-805. https://doi.org/10.1108/K-09-2014-0184

[28] Sagoe, D., Precincts and prospects in the use of focus groups in social and behavioral science research. The Qualitative Report, 2012. 17(29): p. 1-16.

[29] Creswell, J.W., Research design: Qualitative, quantitative, and mixed methods approaches. 2013, London: Sage publications.

[30] Krueger, R.A., Focus groups: A practical guide for applied research. 2014: Sage publications.

[31] Jose, A.F. and R.S. Estoque, A Textbook for an Introductory Course in Sociology, ed. I. Lulu Press. 2010.

[32] Koksal, M.H., The intentions of Lebanese consumers to adopt mobile banking. International Journal of Bank Marketing, 2016. 34(3): p. 327-346. https://doi.org/10.1108/IJBM03-2015-0025

[33] Venkatesh, V., et al., User Acceptance of Information Technology: Toward a Unified View. MIS Quarterly, 2003. 27(3): p. 425-478. https://doi.org/10.2307/30036540 


\section{Authors}

Malik Khlaif Gharaibeh is a Ph.D. candidate at the School of Computer Sciences, Universiti Sains Malaysia (USM), Penang, Malaysia. Goes his Master's Degree in Management Information Systems (MIS) from Arab Academy for Banking and Financial Sciences, Jordan in 2011. His research expertise includes information systems, knowledge management, mobile banking, E-banking and information systems acceptance models and theories.

Muhammad Rafie Mohd Arshad is currently working as an Associate Professor at the School of Computer Sciences, Universiti Sains Malaysia (USM), Penang, Malaysia, where he teaches Management of Information Systems, Multimedia Systems, E-Learning and Virtual Reality. His area of interests includes RFID Applications, Mobile Application for Hajj \& Umrah and IT management. He has various research and publications (e-mail: rafie@usm.my).

Natheer K. Gharaibeh is currently working as Associate Professor at College of Computer Science \& Engineering at Yanbu, Taibah University, Saudi Arabia. in 2011 he worked as a researcher in Rostock Technical University, Germany, he worked as Assistant Professor at, Balqa Applied University. He also worked as part-time Lecturer at Jordan University of Science and Technology (JUST) and other Jordanian universities. He published many papers in International Journals and participated with several International Conferences. His current research interests are: Business Intelligence, Web Engineering, NLP, IR and Knowledge Societies (e-mail: nkgharaibeh@gmail.com).

Article submitted 05 March 2018. Final acceptance 11 July 2018. Final version published as submitted by the authors. 